PROBLEMS

OF MANAGEMENT

IN THE $21^{\text {st }}$ CENTURY

Volume 8,2013

\section{RELATIONS BETWEEN ORGANIZATIONAL EFFECTIVENESS AND EFFICIENCY IN PUBLIC SECTOR UNITS}

\author{
Bernard Ziębicki \\ Cracow University of Economics, Cracow, Poland \\ E-mail: ziebicki@uek.krakow.pl
}

\begin{abstract}
The purpose of this study is to present the relations between organizational effectiveness and efficiency in public sector units. The study was conducted in 114 Polish communes, in the period from January to June 2013. To assess organizational effectiveness the author's model has been applied, which considers criteria referring to the three main concepts of management in the public sector: the traditional public administration, New Public Management and Public Governance. The efficiency assessment was based on the method of DEA (Data Envelopment Analysis). To study the relations between the organizational effectiveness and the efficiency Spearman's rank correlation method and the Wilcoxon signed-rank test have been used.
\end{abstract}

Key words: organizational effectiveness, efficiency, DEA (Data Envelopment Analysis), public sector units.

\title{
Introduction
}

The public sector is present in each country regardless of its socio-political structure or economic development. The state fulfils its basic functions through the public sector, and delivers public goods which, due to their nature or unprofitability cannot be provided by the private sector. Delivering public goods and maintaining public sectors by contemporary countries involves increasing costs. As a result, questions about the efficiency and effectiveness of the public sector are raised more and more often. This problem is also reflected in increasing scientific research. Research undertaken in this respect are most often related to the evaluation of the efficiency of the entire public sector. It usually consists in searching for correlations between expenses in the public sector and various measures of economic growth. However, it should be emphasized that the public sector consists of thousands of organizational units the performance of which does not depend only on system conditions but also on the level of management at single units.

Scientific research concerning the efficiency at the level of single public units is conducted much less frequently. Most often, it consists in the assessment of the examined units on the basis of selected indicators or by applying the stochastic frontier methods. The former approach refers to the assessment of efficiency of services or certain areas of public activity in the examined units. The latter is associated with the comprehensive assessment of the unit from the perspective of technical efficiency. The main method in this respect is DEA (Data Envelopment Analysis). Both the indicator methods and the stochastic frontier methods consist in relative analysis - the comparison between various public units. In the case of indicator methods, this comparison is direct, while in the case of stochastic frontier methods - it applies to a curve, determining the level of "model" efficiency in the set of examined units. However, 
these methods do not provide knowledge about the reasons for a specific level of performance, in particular related to quality and efficiency of management in the examined units.

Such identification is possible by the assessment of organizational effectiveness. This category does not have a precise definition. It is most often presented in the form of multidimensional criteria which make it possible to identify various types of outputs and indicate reasons for a specific level of performance in a given organizational system.

Examining relations between the discussed categories of assessment of the outputs of public units will consist of an analysis of the correlation between the criteria of organizational effectiveness and efficiency in selected units. The implementation of this objective requires, first of all, the development of a model of organizational effectiveness taking into account the special character of management in public sector units. Research concerning the discussed problem has been conducted in 114 randomly selected communes. These units constitute the basic and, at the same time, the most numerous group of public institutions in Poland. The main premise for selecting this type of units was: comparability resulting from identical principles and objectives of their actions and observed differences in the level of comprehensive efficiency occurring between these units. The second criterion of selection was the unit's size. The research was conducted in units employing more than 50 employees. This limitation resulted directly from the assumption that in the case of large units management requires the formation of a specific system and using a set of principles and tools in a formalized manner. The research was conducted in the period from January to June 2013.

\section{Methodology of Research}

\section{Methodology of Efficiency}

Efficiency is one of the basic categories of assessing actions. It is expressed in the form of the relationship between outputs and inputs used to obtain them. It is most often assessed on the basis of various indicators which are examined separately or jointly after their aggregation. The stochastic frontier methods are recently used more and more often in the assessment of the efficiency of organizational units. The basis for analysis in this case is the determination of the production function with the use of classic econometrics estimation tools. The measurement of efficiency consists in determining the deviations of particular units from the determined function. Stochastic frontier methods enable a comprehensive, relative (by comparison with others) assessment of the efficiency of the examined units. Additionally, in the case of these methods, as opposed to indicators, the outputs and inputs do not need to be expressed in the form of financial values. Stochastic frontier methods are divided into: parametric and nonparametric. Parametric methods most often used in the assessment of efficiency include: COLS (Corrected Ordinary Least Squares), FPF (Frontier Production Function), TFA (Thick Frontier Approach), SFA (Stochastic Frontier Approach). On the other hand, non-parametric methods include: DEA (Data Envelopment Analysis) and FDH (Free Disposal Hull). Parametric methods make it possible to analyse efficiency only in the relations of single outputs and inputs. The total assessment of the relations of numerous outputs and inputs is possible by the application of non-parametric methods. The basic non-parametric method to measure efficiency is DEA (Data Envelopment Analysis). In general, it is also the most often applied method for examining technical efficiency.

This method was developed at the end of the 1970s. Its authors are A. Charnes, W. W. Cooper and E. Rhodes (1978). The DEA model may be mathematically presented as the following relation (Baran, 2009): 


$$
E_{j}=\frac{\sum_{r=1}^{s} u_{r} y_{r j}}{\sum_{i=1}^{m} v_{i} x_{i j}}
$$

where:

$E_{j}$ - technical (technological) efficiency,

$s$ - number of effects,

$m$ - number of inputs,

$u_{r}$ - weights determining the significance of particular effects,

$v_{i}$ - weights determining the significance of particular inputs,

$y_{r j}-$ size of effect of $r$ kind $(r=1, \ldots, R)$ in $j$ object,

$x_{i j}$ - size of input of $i$ kind $(\mathrm{n}=1, \ldots, N)$ in $j$ object; $(j=1, \ldots, J)$. 2009):

Information necessary to determine efficiency in the DEA method includes (Guzik,

- set of objects $O_{1} \ldots, O_{j}$;

$-y_{r j}-$ size of effect of $r$ kind $(r=1, \ldots, R)$ in $j$ object,

$-x_{i j}$ - size of input of $i$ kind $(n=1, \ldots, N)$ in $j$ object; $(j=1, \ldots, J)$.

In the article, the DEA method has been used to assess the efficiency of the examined communes. The following has been adopted as categories of outputs:

- own income of commune per 1 inhabitant,

- investment expenses of commune per 1 inhabitant,

- investment expenses on municipal economy and environmental protection per 1 inhabitant,

- obtained European funds per 1 inhabitant,

- business entities registered in the REGON register per 1000 inhabitants.

Inputs have been assessed on the basis of expenses on public administration per 1 inhabitant. Constant effect of scale has been assumed in the analysis. Indexes used in the study are one of the most often used in assessing the activity of communes in Poland.

The analysis from the perspective of input-oriented efficiency (EI) and output-oriented efficiency (EO) has been separately conducted in the research. The former indicates to what extent inputs may be reduced without affecting the level of obtained outputs. This degree defines the distance from the frontier of production capacity determined in this manner. The latter category demonstrates how much outputs may be increased at the current inputs. Conducting the assessment from the perspective of both categories of efficiency is associated with the fact that public sector units may affect both the level of inputs and outputs when maximizing their efficiency.

\section{Methodology of Organizational Effectiveness}

Organizational effectiveness is, on the other hand, a broad category of assessing the outputs of cooperation as part of the organizational system. Research concerning the organizational effectiveness was conducted mainly in Anglo-Saxon countries. The leading researchers from this field include: P.R. Lawrence, W. Lorsch, E. Yuchtman, S. E. Seashore, J.L. Price, D. Lawless, R.M. Steers, J.P. Campbell, W.R. Scott, R.E. Quinn, K.S. Cameron, A. Lewin, J.W. Minton (Cameron, 2010).

Organizational effectiveness is usually presented in the form of multi-dimensional criteria relating to the organization's various attributes.

One of the first attempts to indicate the criteria defining the essence of organizational effectiveness was undertaken by J.P. Campbell. His model covers 30 criteria. These include: overall effectiveness, productivity, efficiency, profit, quality, accidents, growth, absenteeism, turnover, job satisfaction, motivation, morale, control, conflict / cohesion, flexibility / adapta- 
tion, planning and goal setting, goal consensus, internalization of organizational goals, role and norm congruence, managerial interpersonal skills, managerial task skills, information management and communication, readiness, utilization of environment, evaluations by external entities, stability, value of human resources, participation and shared influence, training and development emphasis, achievement emphasis (Campbell, 1979). Campbell's model is one of the most often quoted perspectives of organizational effectiveness in global literature.

The assessment of organizational effectiveness of public sector units requires the development of a model the criteria of which would correspond to the specific nature of management in this area.

The specific character of management in public units was changed along with the evolution of the public sector's role in the country. According to H. Izdebski (2007) we may distinguish three basic stages of development in this respect and corresponding management concepts: traditional public administration, New Public Management, Public Governance.

The first concept is related to the main stage of public administration's development. During that time, the main idea of public administration became public service. Management in the public sector in this period was related to two concepts - the separation of politics and administration (W. Wilson) and the ideal bureaucracy (M. Weber). Its presence in the public administration sector contributed to the ordering of the principles of operation, the transparency of functioning, the formalization of actions, the official hierarchy, the continuity of operation, specialization, the maintenance of discipline, filling positions according to work competencebased requirements, the impartiality of the officials' actions.

The second stage of the public sector's evolution is New Public Management. The basis of this stage is the usage of the principles and methods typical for the private sector in the management of public sector units. Changes in the public sector units introduced within this trend include: decentralization and disaggregation of units, employment reduction, focus on results, implementation of performance management, improving the quality of services, costs reduction, raising economic effectiveness and the efficiency of operation.

The New Public Management model was also quite widely criticized, despite the fact that it contributed to numerous positive changes in the functioning of the public sector worldwide. The main accusation from the opponents of this concept was the assumption of the possibility of transferring management principles and tools used in the private sector to the public sector. In the opinion of numerous researchers, the nature of public activities and the specific character of processes implemented as part of it makes such transfer impossible (Flynn, 2002; Painter, 1997). It has been indicated that administration, as a principle, operates slower than private companies because it needs to take into account much more factors in its activities. Administrative decisions are often long-term and are a result of political influence (Pollitt, 1990; Armstrong, 1998).

The last stage of the public sector's development is Public Governance. The beginnings of this approach date back to the middle of the 1990s. The basic assumption of Public Governance is the incorporation of citizens into the process of governance, on the basis of a partnership. Hard law, being the sum of regulations, more and more often becomes insufficient for good governance and needs to be supplemented with soft law (standards) which will regulate public activity (Hausner, 2008).

The model of organizational effectiveness should thus include criteria referring to all three concepts (Figure 1). The criteria of organizational effectiveness in the proposed model result from the confrontation of assumptions of management in public sector units and the previous achievements with regard to organizational effectiveness.

In the case of the concept of traditional public administration, the main criteria of organizational effectiveness included: stability, control and competency. The stability of examined units has been assessed on the basis of the level of variability $\left(\mathrm{S}_{1}\right)$ and formalization of implemented tasks $\left(\mathrm{S}_{2}\right)$. The effectiveness of control has been assessed through the scope of output control $\left(\mathrm{C}_{1}\right)$. Competency, on the other hand, was examined in two dimensions: from the 
Bernard ZIĘBICKI. Relations between Organizational Effectiveness and Efficiency in Public Sector Units

PROBLEMS

OF MANAGEMENT

IN THE $21^{\text {st }}$ CENTURY Volume 8,2013

106

perspective of the organizational unit and employees. In the first case, it has been evaluated on the basis of the compliance of implemented tasks with the formal scope $\left(\mathrm{Co}_{1}\right)$. In the second case, on the other hand, through the compliance with employee competences and the working post's profile $\left(\mathrm{Co}_{2}\right)$ as well as through the level of expenses for training courses and other forms of supplementary education for employees $\left(\mathrm{Co}_{3}\right)$.

Organizational effectiveness of New Public Management has been evaluated through: performance, optimization of resource use and motivation. Performance was assessed on the basis of two indexes: own incomes of the commune per 1 inhabitant $\left(\mathrm{P}_{1}\right)$ and investment expenses of the commune per 1 inhabitant $\left(\mathrm{P}_{2}\right)$. The assessment of the optimization of resource use was conducted on the basis of a study of opinions concerning the possibility to increase the scope of implemented tasks at the current resource level $\left(\mathrm{O}_{1}\right)$. Motivation, on the other hand, has been assessed through the use of financial bonuses $\left(\mathrm{M}_{1}\right)$ and promoting individual results related to the assessment $\left(\mathrm{M}_{2}\right)$.

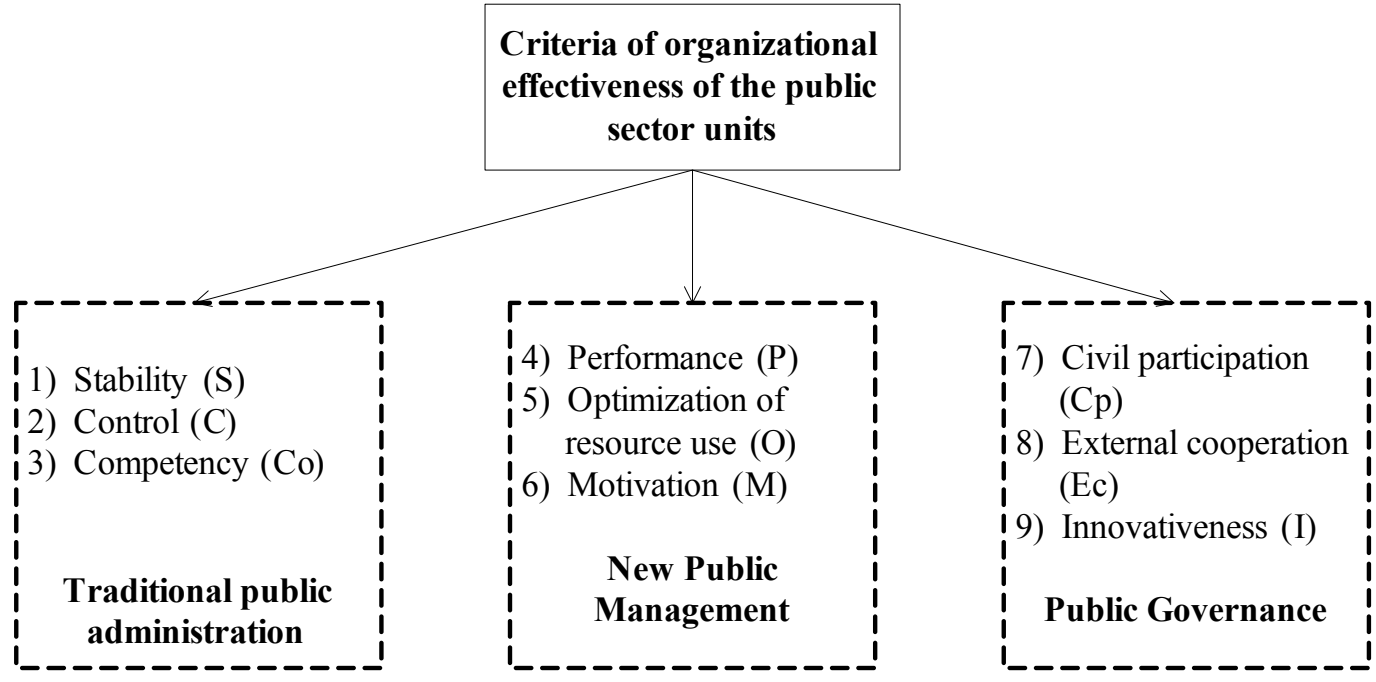

\section{Figure 1: The criteria of organizational effectiveness corresponding to the spe- cific nature of management in public sector units.}

With regard to participatory management (Public Governance), the following criteria of organizational effectiveness have been used: civil participation, external cooperation and innovativeness. The level of civil participation has been assessed on the basis of a 5-grade participation ladder $\left(\mathrm{Cp}_{1}\right)$ (Długosz \& Wygnański, 2005). The scope of external cooperation has been assessed through the number of projects implemented in the form of public-private partnership (PPP) (Ec $)_{1}$. The basis for assessing innovativeness was the number of functional, subjective and organizational innovations implemented by the unit over the past 5 years $\left(\mathrm{I}_{1}\right)$.

Empirical material was collected on the basis of interviews and the analysis of periodical reports from the activities of examined units. A 5-level Likert scale was used to examine the opinions of respondents.

\section{Methodology of Assessment of the Relation between Organizational Effectiveness and Efficiency}

Spearman's rank correlation method and Wilcoxon signed-rank test were used to assess the relations between organizational effectiveness and efficiency. The selection of the listed methods was determined by the character of the analysed data. With regard to organizational 
effectiveness factors assessed on the basis of the study of respondent opinions according to the 5-level Likert scale, the assessment of relations with regard to comprehensive effectiveness has been conducted with the use of both methods. In the case of factors assessed through the number of units using a given solution or the number of results in the unit, it was possible to apply only the Wilcoxon test.

Spearman's rank correlation method may assume values from -1 to 1 . These values are most often interpreted as follows:

$\left|\mathrm{r}_{\mathrm{s}}\right| \leq 0.2$ - vague correlation,

$0.2<\left|\mathrm{r}_{\mathrm{s}}\right| \leq 0.4-$ moderate correlation,

$0.4<\mid$\begin{tabular}{r|}
$\mathrm{r}_{\mathrm{s}}$ \\
$\mathrm{s}$
\end{tabular}$\leq 0.7$ - strong correlation,

$\left|\mathrm{r}_{\mathrm{s}}\right|>0.7$ - very strong correlation.

The correlation's direction is also significant. Positive correlation means that the values of both features change in the same direction. In negative correlation the growth in value of one feature corresponds to the decrease in the other.

Wilcoxon's test is, on the other hand, a non-parametric alternative of the paired Student's t-test, when the assumption about the normality of the observation's difference distribution is not met. The value $p$ determined in the test means the probability of rejecting the zero hypothesis with the identity of distribution of the compared variables. The standard level of significance equal to $\alpha=0.05$ has been adopted in the analysis (Aczel, 2011).

\section{Results of Research and Discussion}

The conducted analysis in most cases did not demonstrate the presence of a strong correlation between the criteria related to organizational effectiveness and comprehensive efficiency considered from the perspective of inputs and outputs. To a great extent this results from the properties of the analysed variables. In this case they are mainly characterized by a high degree of variability and do not form a simple cause and effect system. In such a situation correlations even at a low level may be the basis for deduction on defined tendencies. As it has been mentioned above, the correlation's direction is also significant.

The results of analyses of the discussed dependences have been presented in Table 1.

In the case of criteria of organizational effectiveness related to traditional public administration the highest level of positive correlation occurred between expenses on supplementary education for employees $\left(\mathrm{Co}_{3}\right)$ as well as the compliance between employee competences and the working post's profile $\left(\mathrm{Co}_{2}\right)$ and the efficiency of inputs (EN) $\left(r_{s}=0.22 ; p=0.021\right.$ and $r_{s}$ $=0.17 ; p=0.113)$. These factors may be considered positively affecting the input-oriented efficiency (EI). In the case of the mentioned factors there was also a positive correlation with regard to the output-oriented efficiency (EO). The dependence in this respect was, however, much poorer $\left(r_{s}=0.1 ; p=0.281\right.$ and $\left.r_{s}=0.09 ; p=0.346\right)$. Wilcoxon's test also demonstrated a strong relation between output control $\left(\mathrm{C}_{1}\right)$ and the input-oriented and output-oriented efficiency (EI $\mathrm{p}<0.001$; EO $\mathrm{p}=0.002$ ). This factor should be considered as one substantially affecting comprehensive efficiency.

The lower level of correlation and its negative direction occurred, on the other hand, in the case of the compliance of implemented tasks with the formal scope in the organizational unit $\left(\mathrm{Co}_{1}\right)$ as well as the level of variability of implemented tasks $\left(\mathrm{S}_{1}\right)$ and comprehensive efficiency (both inputs EI as well as outputs EO). These factors should be considered as lowering efficiency. Small positive correlation was also present between formal procedures of task implementation $\left(\mathrm{S}_{2}\right)$ and the input-oriented efficiency (EI) $\left(r_{s}=0.05 ; p=0.601\right)$. With regard to the output-oriented efficiency (EO), this factor was related to negative correlation $\left(r_{s}=-0.06\right.$; $p=0.537)$. 
Bernard ZIĘBICKI. Relations between Organizational Effectiveness and Efficiency in Public Sector Units

PROBLEMS

OF MANAGEMENT

IN THE $21{ }^{\text {st }}$ CENTURY

Volume 8, 2013

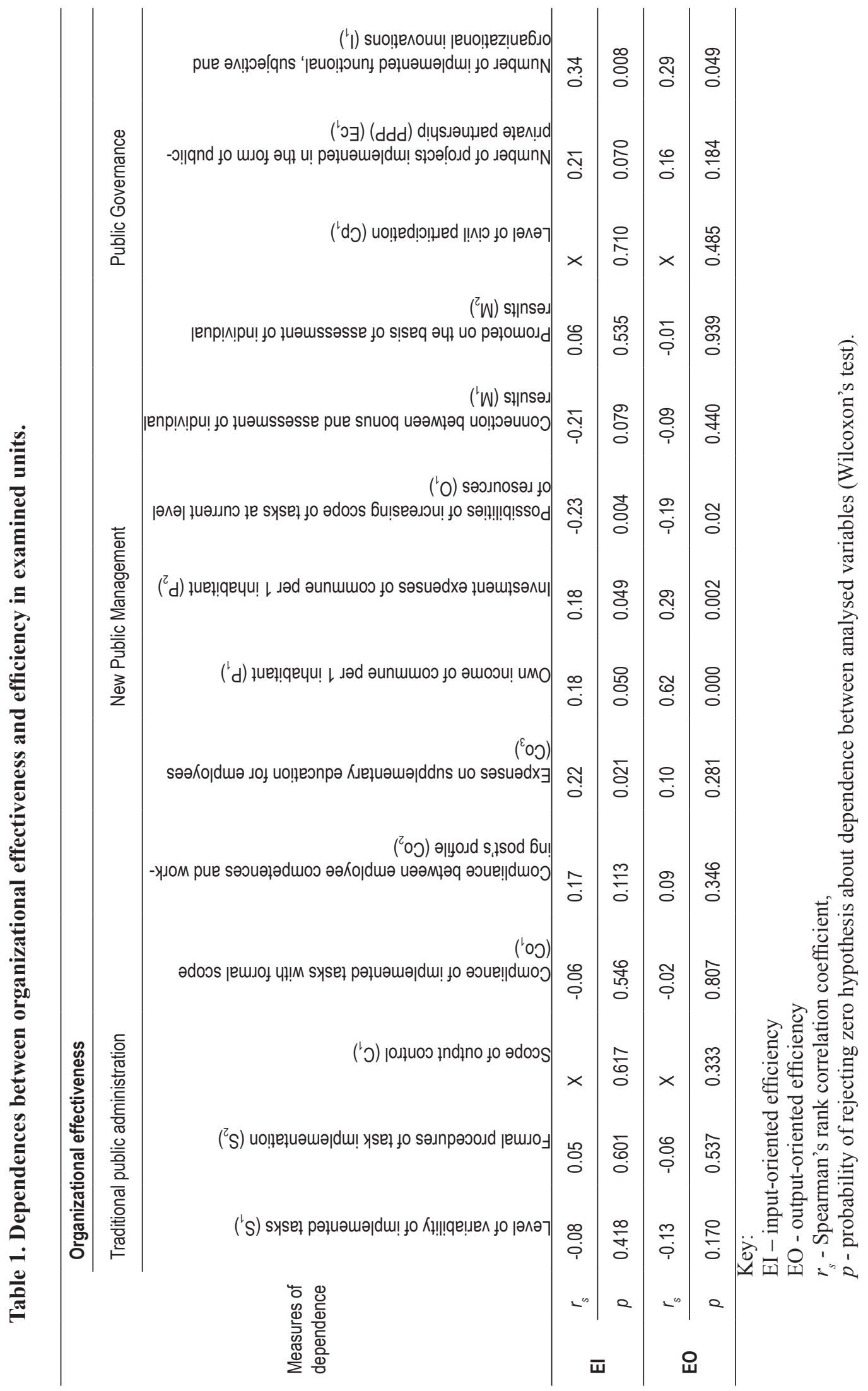


In general, the higher level of correlation occurred between the criteria of organizational effectiveness related to New Public Management and comprehensive efficiency. The highest correlation (strong) in this case occurred between the output-oriented efficiency (EO) and own incomes of the commune $\left(\mathrm{P}_{1}\right)\left(r_{s}=0.62 ; p=0.000\right)$. A relatively high level of impact on the outputs (EO) was also demonstrated by investment expenses $\left(\mathrm{P}_{2}\right)\left(r_{s}=0.29 ; p=0.002\right)$. In the case of the listed factors there was also positive correlation with regard to the input-oriented efficiency (EI) $\left(r_{s}=0.18 ; p=0.050\right.$ and $\left.r_{s}=0.18 ; p=0.049\right)$. These factors may be considered as contributing to the growth in the unit's comprehensive efficiency. Negative correlation occurred between efficiency and the possibility to increase the scope of tasks at the present level of resources $\left(\mathrm{O}_{1}\right)$. This means that the higher reserves indicated by the respondents, the lower the efficiency of units.

The low level of correlation and compliance of the distribution of the analysed variables was also recorded between motivation focused on outputs and comprehensive efficiency. A negative correlation was recorded in the case of a connection between the bonus and the assessment of employee individual results $\left(\mathrm{M}_{1}\right)$. As compared to the input-oriented efficiency (EI) it was on a moderate level $\left(r_{s}=-0.21 ; p=0.079\right)$. With regard to the output-oriented efficiency (EO), the correlation of this factor was insignificant $\left(r_{s}=-0.09 ; p=0.440\right)$. A similar insignificant level of correlation was recorded between promoting employees on the basis of the assessment of individual results $\left(\mathrm{M}_{2}\right)$ and the unit's comprehensive efficiency (EI $r=0.06 ; p=$ $0.535 ; \mathrm{EO} r_{s}=-0.01 ; p=0.939$ ). It demonstrates the lack of impact or even a negative impact of using financial stimuli as well as promotions, focused on individual outputs, on the unit's comprehensive efficiency. The presented thesis confirms the results of previous research, described in literature, indicating the following extra-financial factors as the main sources of motivation in public sector units: stability of employment as well as implementation of tasks of particular significance (Houston, 2000; Buelens, den Van Broeck, 2007).

In the case of the criteria of organizational effectiveness related to the concept of Public Governance, positive correlation on a moderate level was recorded between efficiency and the number of projects conducted as part of public-private partnership $\left(\mathrm{Ec}_{1}\right)\left(\mathrm{EI} r_{s}=0.21 ; p=\right.$ $\left.0.070 ; \mathrm{EO} r_{s}=0.16 ; p=0.184\right)$ and the number of implemented innovations $\left(\mathrm{I}_{1}\right)\left(\mathrm{EI} r_{s}=0.34 ; p\right.$ $=0.008 ; \mathrm{EO} r_{s}=0.29 ; p=0.049$ ). The listed factors should be considered as ones affecting the comprehensive efficiency of the examined communes to the greatest extent.

On the other hand, civil participation in the examined communes does not contribute to the growth in the unit's efficiency (EI $p=0.710$; EO $p=0.485$ ).

\section{Conclusions}

The research demonstrated the presence of dependences between the criteria of organizational effectiveness and efficiency. The strongest positive dependence with regard to efficiency was recorded in the case of expenses for training courses and other forms of supplementary education for employees, acquiring financial funds as well as investment projects, using output control and cooperation as part of public-private partnership and innovations. These factors should be considered as ones contributing to the growth in efficiency. Negative correlation, on the other hand, was recorded between factors related to stability and the formalization of activities as well as using financial bonuses and other motivation stimuli related to the assessment of individual results. The research did not demonstrate dependences between civil participation and efficiency as well. These factors negatively affect the level of efficiency or they do not affect it at all.

The conducted research not only made it possible to identify the impact of organizational effectiveness factors on efficiency in public sector units but also confirmed the need to jointly assess efficiency and organizational effectiveness. This is the only way to obtain wide knowledge on actual reasons for a specific level of overall effectiveness in public sector units. 
Bernard ZIĘBICKI. Relations between Organizational Effectiveness and Efficiency in Public Sector Units

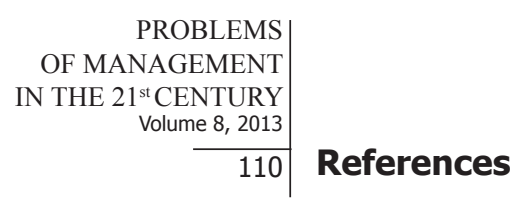

Aczel, A. D. (2011). Statistics for Management. Warsaw: Polish Scientific Publishers PWN.

Armstrong, A. (1998). A Comparative Analysis: New Public Management - The Way Ahead? Australian Journal of Public Administration, 57 (2), 12-14.

Baran, J. (2009). Parametric and non-parametric methods used to measure scale efficiency of dairy cooperatives. Annals of Agricultural Science, 96, series G, 97-106.

Buelens, M., \& Van den Broeck, H. (2007). An Analysis of Differences in Work Motivation between Public and Private Sector Organizations. Public Administration Review, 1 (67), 24-33.

Cameron, K. S. (Ed.) (2010). Organizational effectiveness. US: Edward Elgar Publishing Limited.

Campbell, J. P. (1977). On the nature of Organizational Effectiveness. In: Goldman, P. S. \& Pennings, J. M. (Eds.). New Perspectives on Organizational Effectiveness. San Francisco: Jossey-Bass.

Charnes, A., Cooper, W. W., \& Rhodes, E. (1978). Measuring the efficiency of decision making units. European Journal of Operational Research, 2, 429-444.

Długosz, D., \& Wygnański, J. J. (2005). Citizens also determine. Guide to social participation. Warsaw: Association Forum of Non-Governmental.

Flynn, N. (2002). Explaining New Public Management: The Importance of Context. In: McLaughlin, K. Osborne, O. \& Ferlie E. (Eds.). New Public Management: Current Trends and Future Prospects. London: Routledge.

Guzik, B. (2009). Basic DEA models in the study of economic efficiency and social. Poznań: Economics University.

Hausner, J. (2008). Public management. Warsaw: Scientific Publisher SCHOLAR.

Houston, D. J. (2000). Public-Service Motivation: A Multivariate Test. Journal of Public Administration Research and Theory, 10 (4), 713-728.

Izdebski, H. (2007). From public administration do Public Governance. Public Management, 1, 7-20.

Painter, M. (1997). Public Management: Fad or Fallacy. In: Considine, M. \& Painter, M. (Eds.). Managerialism: The Great Debate, Considine. Carlton South: Melbourne University Press.

Pollitt, Ch. (1990). Managerialism and the Public Services: The Anglo-American Experience. Oxford: Blackwell.

Advised by Janusz Czekaj, Cracow University of Economics, Poland

Received: October 06, 2013

Accepted: November 25, 2013

Bernard Ziębicki

Ph.D., Assistant Professor, Cracow University of Economics, Rakowicka 27

Street, 31-510 Kraków, Poland.

E-mail: ziebicki@uek.krakow.pl 